\title{
Modeling and Parameter Optimization for Surface Roughness and Residual Stress in Dry Turning Process
}

\author{
M. H. El-Axir \\ Mechanical Engineering Dpt \\ Northern Border University \\ Arar, Saudi Arabia \\ ealaxir@yahoo.com
}

\author{
M. M. Elkhabeery \\ Mechanical Engineering Dpt \\ Northern Border University \\ Arar, Saudi Arabia \\ mmkhabeery@yahoo.com
}

\author{
M. M. Okasha \\ Mechanical Engineering Dpt \\ Northern Border University \\ Saudi Arabia (on leave from \\ Mechanical Engineering Dpt, \\ Faculty of Industrial Education, \\ Helwan University, Egypt) \\ abobanno@yahoo.com
}

\begin{abstract}
The influence of some turning variables and tool overhang on surface roughness parameters and residual stress induced due to machining 6061-T6 aluminum alloy is investigated in this paper. Four input parameters (cutting speed, feed rate, depth of cut and tool overhang) are considered. Tests are carried out by precision turning operation on a lathe. Design of experiment techniques, i.e. response surface methodology (RSM) and Taguchi's technique have been used to accomplish the objective of the experimental study. Surface roughness parameters are measured using a portable surface roughness device while residual stresses are measured employing deflectionetching technique using electrochemical analysis. The results obtained reveal that feed and rotational speed play significant role in determining the average surface roughness. Furthermore, the depth of cut and tool overhang are less significant parameters, whereas tool overhang interacts with feed rate. The best result of surface roughness was obtained using low or medium values of overhang with low speed and /or feed rate. Minimum maximum tensile residual stress can be obtained with a combination of tool overhang of $37 \mathrm{~mm}$ with very low depth of cut, low rotational speed and feed rate of $0.188 \mathrm{~mm} / \mathrm{rev}$.
\end{abstract}

Keywords-Al-6061-T; RS; surface roughness parameters; residual stress; turning parameters

\section{INTRODUCTION}

Aluminum alloys have high demand in many engineering applications because of their excellent mechanical properties. Any production activity is performed with main objectives of good surface quality and higher production rate. Metal machining process output is highly dependent on input variables, since small variations in one of the input variables results in a considerable change in the output variables. The integrity of the surface produced in machining (process output) is recognized to have a significant impact on product performance and life time. Surface integrity represents the nature of the surface condition of a workpiece after manufacturing/machining. There are two aspects of surface integrity: surface topography characteristics and subsurface layer characteristics. The surface topography comprises of surface roughness, waviness, form errors, and flaws whereas the subsurface layer characteristics that can change due to processing include plastic deformation, residual stresses, cracks, hardness, phase changes, re-crystallization and intergranular attack [1-3]. In addition to the longitudinal feed, cutting speed and depth of cut, geometry of the tool and stability of machine tool also influences the all surface integrity elements. Influence of cutting parameters on cutting force and surface finish was investigated in authors in [4]. Feed rate was found to have significant influence on cutting force as well as surface roughness. Depth of cut was found to have significant influence on cutting force, but has an insignificant influence on surface roughness. Authors in [5] studied the effects of tool overhang on selection of machining parameters and surface finish. They found that too large and very small tool overhangs result in poor surface finish. Further, optimum range of tool overhang with minimum tool vibrations was established. In [6], authors studied the effect of turning the aluminum with tools having different cutting edge materials and tool edges shapes on the surface roughness. Authors in [7] investigated the effect of high speed turning of Al 7075 which is a high strength aluminum alloy. Authors in [8] used Taguchi robust design principles to optimize the process parameters in turning A16061 alloy for MRR and surface roughness with single objective optimization.

Residual stress generation cannot be avoided after machining processes. Residual stress is a major component of surface integrity and is identified as a key factor that influences fatigue life, dimension accuracy and corrosion resistance of machined components. Thus, the residual stress in a machined layer has been studied by many researchers. The majority of research work on residual stresses in metal cutting has been limited to experimental study [9-13]. Despite these efforts, the quantitative relationship between cutting conditions and residual stresses is still unknown due to the inherent complexity nature of the formation of residual stresses in metal cutting. A part of the recent research work in this field was 
based on the finite element models while others used different approaches to tackle the problem ranging from mathematical modeling to metallurgical investigations. The results presented in [14] show that material hardness has a direct and significant influence on the value of residual stress resulted by machining. It was reported that since the method of machining hardened steel differs from that of machining soft steel, the machined surface of soft steel does not show any stage of phase transformation. Authors in [15] reported a case of deformation in machined surfaces of hardened steels and found that the residual stresses in soft steels are mostly tensile stresses while those remaining in hardened steels are mostly compressive stresses. Another research which was conducted on two types of steel which have been machined by turning reported that residual stresses are influenced, to a great extent, by feed rate and nose radius and, to a certain extent, by the cutting speed and the rake angle. The results of the experiments conducted in $[16,17]$ show that the residual stresses of the tensile type is generated at the surface of many materials machined by milling in the presence of coolants. It was also showed that maximum residual stress increases with an increase in feed rate, depth of cut and the tensile stress of the workpiece material. Authors in [18] investigated the effect of cutting variables (cutting speed, feed rate, depth of cut, geometry, and coating) on residual stresses in turning operations and reported that residual stresses on stainless steel components are due to plastic deformation and thermal effect on tool nose. The effect of high cutting speeds and feed rate on residual stresses on different hard steel materials has been investigated [19-21]. The residual stresses on the surface are of the compressive type and they increase downwards below the surface to the maximum at a certain depth, then decrease with further depth. Taguchi method is widely used for optimizing industrial/production processes. The Taguchi design optimization method can be divided into three stages: (a) system design, (b) parameter design and (c) tolerance design. Among the three stages, the parameter design stage is considered to be the important stage. The steps followed in the Taguchi parameter design are: selecting the proper orthogonal array (OA), running experiments based on the $\mathrm{OA}$, analyzing data, identifying the optimum condition and conducting confirmation runs [22]. Many researchers have used the Taguchi method to optimize the various machining operations like turning, end milling, drilling, etc. in various alloys [23-28].

One approach to determine the relationship between various input parameters (independent variables) and responses (output variables) is response surface methodology (RSM), which also ascertains the significance of these parameters on the responses [29]. The main objective of the this work is to study the effects of tool overhang in addition to some turning parameters such as speed, feed rate and depth of cut on some surface integrity phases, namely surface roughness parameters and residual stress. The experiments were carried out on 6061-T6 aluminum alloy under dry conditions. Turning operations are conducted on a CNC turning machine. The Taguchi analysis is applied to obtain the optimal parameter combination using the experimental results. Furthermore, analysis of variance (ANOVA) was also carried out to examine the most significant factors for surface roughness parameters and residual stresses in the turning process. The RSM approach is applied to deduce mathematical models that relate the different input parameters to each response studied in this work.

\section{EXPERIMENTAL WORK}

\section{A. Workpiece Material}

In this work, 6061-T6 aluminum alloy was used as workpieces material. This material was selected because of its importance and wide applications in industry. The chemical composition in weight percent and the mechanical properties are presented in Tables I and II.

TABLE I. THE CHEMICAL COMPOSITION OF 6061-T6 ALUMINUM ALLOY WORK MATERIAL

\begin{tabular}{|c|c|c|c|c|c|}
\hline Element & $\mathbf{M g}$ & $\mathbf{S i}$ & $\mathbf{F e}$ & $\mathbf{C u}$ & $\mathbf{M n}$ \\
\hline $\begin{array}{c}\text { Weight } \\
\text { percent }\end{array}$ & $0.8-1.2$ & $0.80-0.40$ & 0.70 & $0.15-0.40$ & 0.15 \\
\hline Element & $\mathbf{C r}$ & $\mathbf{Z i}$ & $\mathbf{T i}$ & $\mathbf{A l}$ & \\
\hline $\begin{array}{c}\text { Weight } \\
\text { percent }\end{array}$ & $\begin{array}{c}0.04- \\
0.35\end{array}$ & 0.25 & 0.15 & Balance & \\
\hline
\end{tabular}

TABLE II. THE MECHANICAL PROPERTIES OF 6061-T6 ALUMINUM ALLOY WORK MATERIAL

\begin{tabular}{|c|c|c|}
\hline Tensile Strength, MPa & Yield Stress, MPa & Elongation, $\%$ \\
\hline 428 & 355 & 10 \\
\hline
\end{tabular}

\section{B. Workpiece Preparation}

The materials were received in the form of bars with a diameter of $80 \mathrm{~mm}$ and were prepared into two groups. The first group (shown in Figure 1) was used to study the effect of input parameters on the surface profile parameters where the second group (shown in Figure 2) was used to study the input parameters on residual stresses. In the case of the first group, each workpiece was divided into five parts with four recesses for machining with different turning conditions whereas in the case of second group, the raw material was machined into ring shapes with the dimensions shown in Figure 2.

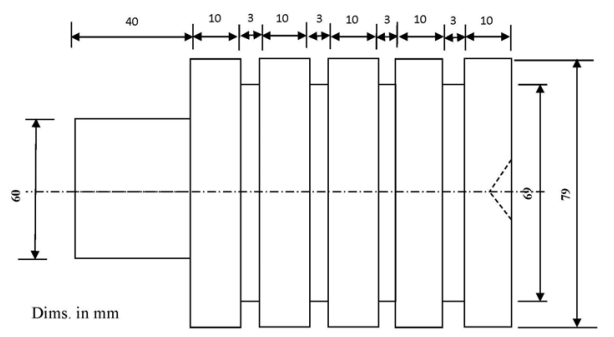

Fig. 1. Workpiece geometry of the first group

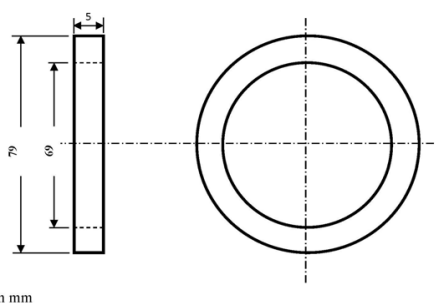

Dims. in mm

Fig. 2. Workpiece geometry of the second group 


\section{Experimental Procedure}

The experimental work was conducted on a $\mathrm{CNC}$ lathe (Model EDU VR1-Lathe). The main advantage of using such a machine is its flexibility. It enables the turning operations to be accomplished easily in a sequential order. Any change in the turning conditions can be easily adjusted. In order that the effect of each parameter on the surface characteristics of the workpiece can be well studied, only four turning parameters were chosen namely, turning speed $n$, feed rate $f$, depth of cut $d$ and tool overhang t. The cutting tool overhang affects the surface quality, especially during the turning process, although this has not been reviewed much. Based on application and theoretical approaches, it is known that cutting tools need to be clamped as short as possible to achieve the desired surface quality of the workpiece. In this work, the speed was selected in the range of 165: $2000 \mathrm{rpm}$, turning feed rate was selected in the range of 0.068: $0.468 \mathrm{~mm} / \mathrm{rev}$, depth of cut was selected in the range of 100: $500 \mu \mathrm{m}$. The turning process parameters and their ranges are given in Table III. Dry machining is more popular in manufacturing as a means of reducing overhead costs and protecting the environment [30]. It has great significance for the factors of both economics and environment [31]. Hence, the experiments were carried out under dry (unlubricated) conditions.

TABLE III. TURNING PARAMETERS WITH RANGE AND VALUES AT FIVE LEVELS

\begin{tabular}{|c|c|c|c|c|c|}
\hline Code & $\mathbf{1}$ & $\mathbf{2}$ & $\mathbf{3}$ & $\mathbf{4}$ & $\mathbf{5}$ \\
\hline $\begin{array}{c}\text { Tool } \\
\text { overhang } \\
\mathbf{t}, \mathbf{m m}\end{array}$ & 27 & 32 & 37 & 42 & 47 \\
\hline $\begin{array}{c}\text { Turning } \\
\text { speed } \\
\mathbf{n}, \mathbf{r p m}\end{array}$ & 165 & 300 & 550 & 1100 & 2000 \\
\hline $\begin{array}{c}\text { Feed rate } \\
\text { f, mm /rev }\end{array}$ & 0.068 & 0.117 & 0.188 & 0.272 & 0.468 \\
\hline $\begin{array}{c}\text { Depth of cut } \\
\text { d, } \boldsymbol{\mu m}\end{array}$ & 100 & 200 & 300 & 400 & 500 \\
\hline $\begin{array}{c}\text { Cutting } \\
\text { Conditions }\end{array}$ & \multicolumn{5}{|c|}{ Unlubricated (Dry) } \\
\hline
\end{tabular}

The surface roughness parameters ( $\mathrm{Ra}, \mathrm{Rp}, \mathrm{Rt}, \mathrm{Rz}$, and Rsm) of each turning specimen was measured with a TAYLOR HOPSON surface roughness tester. All the measurements were carried out with a cut off length of $0.8 \mathrm{~mm}$ and for each portion the average of three readings was used. The identification of residual stresses in the machined surface region was achieved by the Deflection Etching Technique method using electrochemical analysis. This method depends on the fact that the machined parts containing residual stresses will undergo shape variation due to removal of layers from the machined surface. The removal of external layers by electrochemical analysis results in elimination of part of the residual stresses which, in turn, leads to redistribution of the residual stresses to the equilibrium position which results in shape variation. This shape variation will be measured, and by then the angle of deviation of the residual stresses can be calculated. When the machining on the ring is finished, the test specimen is prepared by drawing (marking) two parallel lines on the surface of the ring $5 \mathrm{~mm}$ apart and perpendicular to the periphery of the ring, then a third line perpendicular to the parallel lines is marked.
The distance between the parallel lines along the perpendicular line is then measured.

By then the rings are cut or sheared in a position between the two parallel lines, this will result in elimination of a part of the residual stresses causing a change in ring circularity. The distance between the two parallel lines is measured once more, the change in reading of the distance can be either positive or negative, depending on the type of net residual stresses either being tensile or compressive stresses respectively. The ring is then sectioned into two parts in such a way that one of them is extended $5 \mathrm{~mm}$ beyond the line presenting the diameter of the ring. The three unmachined surfaces of the ring are coated with an isolating and corrosion resistance coating. The small section of the ring will be used for the determination of material removal rates. This is done by electrolytic analysis. The part is immersed in the electrolyte, as shown in Figure 3, which shows the set-up of the apparatus prepared for this purpose. The part will be electrolytically etched. Etching is done in intervals of 5 minutes each. The decrease in the thickness is measured in each time, while the average thickness is found by weighing the specimen before and after etching. Etching can be done in a wide range of voltage and current, but the satisfactory conditions are achieved when $75 \mathrm{mg}$ sodium chloride is dissolved in 1 liter of water at current density of $3.3 \mathrm{~mA} / \mathrm{mm}$. The bigger section is used for determining the average residual stresses distribution. A magnification arm is attached to this part with a small mirror at the end and a laser pointer is used to measure angular deflection of the specimen while being etched (Figure 3).

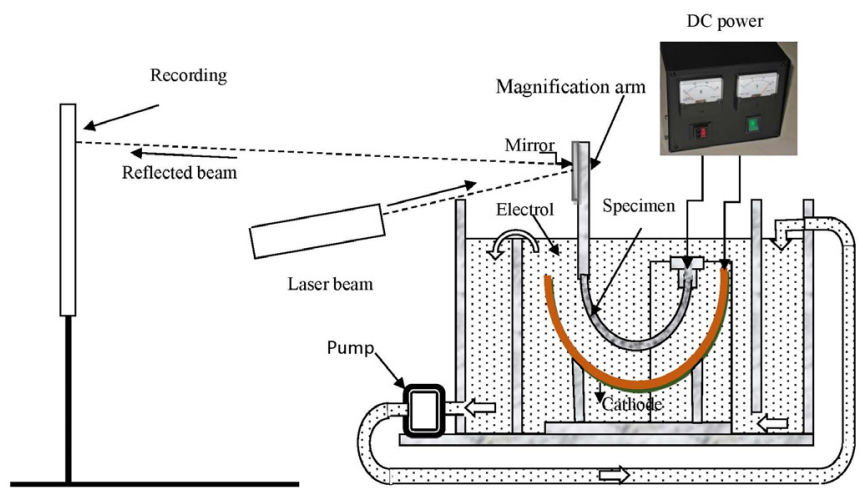

Fig. 3. Experimental set-up of the electrolytic dissolution of workpiece material for measurement angular deviation

It is worth mentioning that ring deflection consists of displacement and rotation components, but the application of this method enables measurement of rotation components only. The residual stresses relieved due to the removal of a certain layer consists of three components: stresses relieved due to removal of $n^{\text {th }}$ layer of metal, stresses relieved due to removal of previous layer, and stresses relieved due to initial cut of the ring. These stresses can be calculated as follows:

1) Stresses relieved due to removal of present layer:

$\sigma_{n, c}=E t 2 \varepsilon / 3 p R d t$ 
where $\mathrm{E}$ is modulus of elasticity, $\mathrm{t}$ is ring thickness, $\varepsilon$ is angular rotation, $\mathrm{R}$ is ring radius.

2) Stresses relieved due to removal of previous layers:

$$
\sigma_{n, p}=A\left[\Delta_{n}\left(4 t_{o}-4 n \Delta t\right)-2 \Delta t(\Delta n-1+\ldots .+\Delta 1)(2)\right.
$$

where $A$ is ring deflection due to removal of $n$ layers, $t_{0}$ is initial ring thickness, $\Delta t$ is change in thickness due to etching

3) Stresses relieved due to initial sectioning of the ring:

$$
\sigma_{n, i}=\left[\Delta D E / 2 R^{2}\right]\left[z-t_{o} / 2\right]
$$

where $\Delta \mathrm{D}$ is the change in ring diameter due to initial sectioning, $\mathrm{z}$ is the remaining ring thickness, $\mathrm{t}_{\mathrm{o}}$ is the initial ring thickness.

The total residual stresses relieved are then:

$$
\sigma_{n, t}=\sigma_{n, c}+\sigma_{n, p}+\sigma_{n, i}
$$

It is worth to mention that the calculated residual stresses are the stresses towards the periphery of the circle; the axial and radial components of residual stresses are in fact small enough and can be ignored. More details about the Deflection Etching Technique are given in [32].

\section{EXPERIMENTAL DESIGN}

To evaluate the effects of turning parameters on some performance characteristics (surface roughness parameters and maximum residual stress) and to identify the performance characteristics under the optimal turning parameters, a specially designed experimental procedure is required. Classical experimental design methods are complex and difficult to use. Additionally, larger number of experiments has to be carried out when number of turning parameters increases. In this study, the main objective is to investigate the effect of the turning parameters (cutting conditions and tool overhang) on both surface roughness parameters and residual stresses generated in the work material. For the purpose of minimizing the experimental work, a simple and adequate experimental design named Taguchi design is used. The Taguchi method involves reducing the variation in a process through robust design of experiments. The overall objective of the method is to produce high quality product at a low cost. In this method, a loss function is used to calculate the deviation between the experimental value and the desired value. This loss function is further transformed into a signal-to-noise $(\mathrm{S} / \mathrm{N})$ ratio $(\eta, \mathrm{dB})$. There are several $\mathrm{S} / \mathrm{N}$ ratios available depending on the type of characteristics; lower is better (LB), nominal is better (NB) and higher is better (HB) [22]. The experimental program was planned in accordance with the principles of experimental design suggested by Taguchi technique with 4 input parameters each having 5 levels and involves 25 experimental observations. The scheme of experimentation adopted in the

\begin{tabular}{|c|c|c|c|c|c|c|c|c|c|c|c|c|c|c|c|c|}
\hline \multirow{2}{*}{$\begin{array}{c}\text { Exp. } \\
\text { No }\end{array}$} & \multicolumn{4}{|c|}{ Input parameters } & \multicolumn{5}{|c|}{ Surface profile parameters } & \multirow{2}{*}{$\begin{array}{c}\begin{array}{c}\text { Resid } \\
\text { ual } \\
\text { stress }\end{array} \\
\begin{array}{c}\text { RS, } \\
\text { MPa }\end{array}\end{array}$} & \multicolumn{5}{|c|}{$\mathrm{S} / \mathrm{N}$ ratios } & \multirow[b]{2}{*}{$\mathbf{R S}$} \\
\hline & $\leftarrow \Xi$ & $=\underline{\Xi}$ & थ छ 巳 & $\tau \equiv$ & $\begin{array}{l}\text { Ra, } \\
\mu \mathrm{m}\end{array}$ & $\begin{array}{l}\mathrm{Rp} \\
\mu \mathrm{m}\end{array}$ & $\begin{array}{l}\text { Rt, } \\
\mu \mathrm{m}\end{array}$ & $\begin{array}{l}\text { Rz, } \\
\mu \mathrm{m}\end{array}$ & $\begin{array}{c}\text { Rsm, } \\
\mu \mathrm{m}\end{array}$ & & $\mathbf{R a}$ & $\mathbf{R p}$ & $\mathbf{R t}$ & $\mathbf{R z}$ & Rsm & \\
\hline 1 & 27 & 165 & 0.068 & 100 & 1.41 & 3.800 & 10.45 & 8.300 & 67.50 & 130 & -2.6 & -11.1 & -19.9 & -17.8 & -37.5 & -41.4 \\
\hline 2 & 27 & 300 & 0.117 & 200 & 2.27 & 5.650 & 13.65 & 11.75 & 121.5 & 170 & -7.9 & -15.4 & -23.2 & -21.9 & -40.5 & -45.0 \\
\hline 3 & 27 & 550 & 0.188 & 300 & 4.49 & 10.84 & 28.42 & 14.00 & 180.4 & 160 & -13.7 & -21.5 & -29.5 & -24.6 & -45.5 & -44.4 \\
\hline 5 & 27 & 2000 & 0.498 & 500 & 11.6 & 26.20 & 57.90 & 51.10 & 395.0 & 110 & -20.3 & -27.8 & -34.5 & -33.3 & -51.2 & -41.3 \\
\hline 6 & 32 & 165 & 0.117 & 300 & 2.09 & 5.400 & 16.35 & 12.35 & 98.00 & 150 & -5.9 & -13.9 & -23.3 & -20.4 & -39.8 & -44.3 \\
\hline 7 & 32 & 300 & 0.188 & 400 & 4.04 & 8.700 & 21.70 & 18.35 & 153.5 & 170 & -11.9 & -19.1 & -27.2 & -25.6 & -43.4 & -44.2 \\
\hline 8 & 32 & 550 & 0.272 & 500 & 6.50 & 14.75 & 30.75 & 26.20 & 217.0 & 150 & -16.4 & -23.5 & -29.7 & -28.9 & -46.7 & -42.6 \\
\hline 9 & 32 & 1100 & 0.468 & 100 & 12.6 & 27.70 & 57.45 & 58.47 & 404.2 & 50 & -22.5 & -28.5 & -35.3 & -35.5 & -51.6 & -36.1 \\
\hline 10 & 32 & 2000 & 0.068 & 200 & 2.39 & 5.700 & 15.40 & 12.45 & 52.50 & 135 & -7.6 & -15.8 & -24.6 & -22.4 & -35.3 & 41.0 \\
\hline 11 & 37 & 165 & 0.188 & 500 & 3.34 & 7.290 & 17.00 & 18.35 & 194.2 & 150 & -10.4 & -16.8 & -30.3 & 24.1 & -45.8 & -43.8 \\
\hline 12 & 37 & 300 & 0.272 & 100 & 8.50 & 14.60 & 35.95 & 37.00 & 277.5 & 100 & -18.3 & -23.3 & -35.3 & -31.2 & -49.1 & -39.5 \\
\hline 14 & 37 & 1100 & 0.068 & 300 & 2.90 & 6.200 & 16.80 & 11.00 & 106.0 & 125 & -9.5 & -16.7 & -28.2 & -22.2 & -39.3 & -41.4 \\
\hline 15 & 37 & 2000 & 0.11 & 400 & 3.94 & 10.15 & 27.00 & 19.90 & 99.00 & 120 & -11.8 & -19.6 & -29.4 & -26.2 & -40.5 & -42.4 \\
\hline 16 & 42 & 165 & 0.272 & 200 & 5.10 & 10.36 & 27.76 & 22.23 & 264.0 & 130 & -14.2 & -20.5 & -34.3 & -28.0 & -47.8 & -43.5 \\
\hline 17 & 42 & 300 & 0.468 & 300 & 11.2 & 22.00 & 55.00 & 45.00 & 360.0 & 160 & -20.3 & -26.2 & -24.1 & -32.0 & -52.2 & -42.9 \\
\hline 18 & 42 & 550 & 0.068 & 400 & 2.24 & 6.800 & 18.45 & 12.35 & 75.00 & 140 & -6.6 & -15.6 & -24.1 & -20.0 & -36.8 & -44.3 \\
\hline 19 & 42 & 1100 & 0.117 & 500 & 3.08 & 6.800 & 16.23 & 14.16 & 108.3 & 165 & -10.2 & -17.5 & -24.8 & -23.9 & -41.4 & -43 \\
\hline 20 & 42 & 2000 & 0.188 & 100 & 5.88 & 12.70 & 30.45 & 25.90 & 187.0 & 90 & -16.1 & -22.8 & -30.4 & -29.1 & -44.9 & -38.9 \\
\hline 21 & 47 & 165 & 0.468 & 400 & 5.60 & 13.00 & 40.65 & 25.65 & 390.0 & 200 & -15.9 & -23.8 & -33.1 & -30.2 & -51.6 & -44.6 \\
\hline 22 & 47 & 300 & 0.068 & 500 & 1.45 & 3.850 & 9.150 & 7.600 & 74.50 & 170 & -3.4 & -11.7 & -19.4 & -18.1 & -37.5 & -46.2 \\
\hline 23 & 47 & 550 & 0.117 & 100 & 3.28 & 7.650 & 17.65 & 14.70 & 117.5 & 140 & -9.8 & -17.7 & -25.4 & -23.2 & -41.3 & 42.25 \\
\hline 24 & 47 & 1100 & 0.188 & 200 & 6.08 & 13.33 & 37.65 & 28.73 & 192.6 & 145 & -14.6 & -21.2 & -29.8 & -27.5 & -46.1 & 43.24 \\
\hline 25 & 47 & 2000 & 0.272 & 300 & 8.03 & 19.33 & 54.20 & 37.50 & 264.3 & 140 & -18.3 & -25.5 & -34.7 & -30.8 & -48.2 & 43.39 \\
\hline
\end{tabular}
present study is given in Table IV.

TABLE IV. EXPERIMENTAL DESIGN ORTHOGONAL ARRAY OBSERVED VALUES AND S/N RATIOS 
It should be pointed out here that the $\mathrm{S} / \mathrm{N}$ ratio analysis is used to find out the optimum machining conditions. The ANOVA analysis is used to find the percentage contribution of each of the input parameters on surface roughness and maximum residual stress. Response surface methodology (RSM) quantifies the relationship between the controllable input parameters and the obtained response surfaces. Also, RSM is a collection of mathematical and statistical techniques useful for analyzing problems in which several independent variables (parameters) influence a dependent variable (response-surface roughness and residual stress), and the goal is to optimize this response [33].

\section{RESULTS AND DISCUSSION}

\section{A. Analysis of Signal to Noise ( $S / N)$ Ratio}

Taguchi uses $\mathrm{S} / \mathrm{N}$ ratio to measure the quality characteristic deviating from the desired value. Typically a smaller value of surface roughness and/or residual stress is desirable to obtain high surface quality and overcome the fracture of the material. Thus, smaller-the-better for surface roughness and residual stress were selected during the present work. The mean $\mathrm{S} / \mathrm{N}$ ratio for each level of the cutting parameters are computed and shown in Table V. Regardless of the lower-the-better or the higher-the better quality characteristic, the greater the $\mathrm{S} / \mathrm{N}$ ratio corresponds to the smaller variance of the output characteristics around the desired value. Therefore, from Table V, it can be seen that the optimal turning performance for the average surface roughness (maximum signal to noise ratio value) was obtained at tool overhang $27 \mathrm{~mm}$ (Level 1), rotational speed of $165 \mathrm{rpm}$ (Level 1), feed rate of $0.068 \mathrm{~mm} / \mathrm{rev}$ (Level 1) and $500 \mu \mathrm{m}$ as a depth of cut (Level 5) settings. The optimal turning performance for minimizing the maximum residual stress was obtained at tool overhang $37 \mathrm{~mm}$ (Level 3), rotational speed of $1100 \mathrm{rpm}$ (Level 4), feed rate of 0.468 $\mathrm{mm} / \mathrm{rev}$ (Level 5) and $100 \mu \mathrm{m}$ as a depth of cut (Level 1) settings.

\section{B. Analysis of Variance}

Analysis of variance (ANOVA) [22] was carried out for a level of significance of $5 \%$, i.e. for $95 \%$ level of confidence. The purpose of ANOVA is to investigate which turning parameter significantly affects the performance characteristics [23]. Table VI shows the results of ANOVA for surface roughness $\mathrm{Ra}$ and maximum residual stress. From the analysis of the average surface roughness data (Table VI), it is observed that feed rate has the most significant effect on the surface roughness and its contribution is $82.21 \%$ followed by rotational speed $(9.5 \%$ contribution), depth of cut $(2.56 \%$ contribution $)$ and tool overhang (1.97\% contribution). From the analysis of the maximum residual stress data, it is observed that depth of cut $(48.12 \%$ contribution) and tool overhang $(25.2 \%$ contribution) play significant role in determining the maximum residual stress. Furthermore, the rotational speed $(8.99 \%$ contribution) and feed rate $(11.68 \%$ contribution $)$ are lesssignificant parameters.

\section{Mathematical Models}

Table IV shows the arrangement and the results of the 25 experiments carried in this work based on the Taguchi technique. These results are used to deduce the mathematical models, according response surface methodology (RSM), which is one of the main objectives of this work. This section presents a study of the development of response models for external turning in terms of tool overhang $\left(\mathrm{X}_{1}\right)$, in addition to cutting conditions, namely; rotational speed $\left(\mathrm{X}_{2}\right)$, feed rate $\left(\mathrm{X}_{3}\right)$, and depth of cut $\left(\mathrm{X}_{4}\right)$. Three reading tests were made on the surface of each specimen and the mean value was calculated and presented in Table IV. Using these results, the response surface for five different profile parameters $\mathrm{Ra}, \mathrm{Rp}, \mathrm{Rt}, \mathrm{Rz}$, and $\mathrm{Rsm}$ as functions of the four parameters used in this work are deduced as the following models:

$\mathrm{R}_{\mathrm{a}}=-0.09556+1.3999 \mathrm{X}_{1}-0.298 \mathrm{X}_{2}-0.0736 \mathrm{X}_{3}+0.1138 \mathrm{X}_{4}-$ $0.2317 \mathrm{X}_{1}{ }^{2}+0.0865 \mathrm{X}_{2}^{2}+0.6218 \mathrm{X}_{3}^{2}-0.1135 \mathrm{X}_{4}^{2}+$ $0.3753 \mathrm{X}_{1} \mathrm{X}_{2}-0.426 \mathrm{X}_{1} \mathrm{X}_{3}+0.0147 \mathrm{X}_{1} \mathrm{X}_{4}+0.0518 \mathrm{X}_{2} \mathrm{X}_{4}$

$\mathrm{R}_{\mathrm{p}}=2.003+0.4699 \mathrm{X}_{1}-1.767 \mathrm{X}_{2}-0.2159 \mathrm{X}_{3}+1.923 \mathrm{X}_{4}-$ $0.096 \mathrm{X}_{1}^{2}+0.041 \mathrm{X}_{2}^{2}+1.383 \mathrm{X}_{3}^{2}-0.410 \mathrm{X}_{4}^{2}+0.924 \mathrm{X}_{1} \mathrm{X}_{2}-$ $1.057 \mathrm{X}_{1} \mathrm{X}_{3}+0.036 \mathrm{X}_{1} \mathrm{X}_{4}-0.011 \mathrm{X}_{2} \mathrm{X}_{4}$

$\mathrm{R}_{\mathrm{t}}=5.999-3.293 \mathrm{X}_{1}-6.342 \mathrm{X}_{2}+1.086 \mathrm{X}_{3}+9.0515 \mathrm{X}_{4}+$ $0.469 \mathrm{X}_{1}^{2}+0.563 \mathrm{X}_{2}^{2}+2.449 \mathrm{X}_{3}^{2}-1.82 \mathrm{X}_{4}^{2}+1.75 \mathrm{X}_{1} \mathrm{X}_{2}-$ $1.63 \mathrm{X}_{1} \mathrm{X}_{3}+0.168 \mathrm{X}_{1} \mathrm{X}_{4}+0.216 \mathrm{X}_{2} \mathrm{X}_{4}$

$\mathrm{R}_{\mathrm{z}}=6.092+4.969 \mathrm{X}_{1}-7.0534 \mathrm{X}_{2}+2.696 \mathrm{X}_{3}-0.345 \mathrm{X}_{4}-$ $0.762 \mathrm{X}_{1}^{2}+0.588 \mathrm{X}_{2}^{2}+2.44 \mathrm{X}_{3}^{2}-0.481 \mathrm{X}_{4}^{2}+1.737 \mathrm{X}_{1} \mathrm{X}_{2}-$ $2.424 \mathrm{X}_{1} \mathrm{X}_{3}+0.407 \mathrm{X}_{1} \mathrm{X}_{4}+0.101 \mathrm{X}_{2} \mathrm{X}_{4}$

$\mathrm{R}_{\mathrm{sm}}=59.132+5.7456 \mathrm{X}_{1}-12.836 \mathrm{X}_{2}+9.229 \mathrm{X}_{3}-1.647 \mathrm{X}_{4}+$ $0.552 \mathrm{X}_{1}^{2}+2.231 \mathrm{X}_{2}^{2}+13.95 \mathrm{X}_{3}^{2}-1.293 \mathrm{X}_{4}^{2}+0.475 \mathrm{X}_{1} \mathrm{X}_{2}-$ $4.77 \mathrm{X}_{1} \mathrm{X}_{3}+1.98 \mathrm{X}_{1} \mathrm{X}_{4}-0.865 \mathrm{X}_{2} \mathrm{X}_{4}$

Mathematical model combining machining parameters with the maximum residual stress (MRS) was also generated as follows:

$\mathrm{MRS}=134.3-51.45 \mathrm{X}_{1}+43.56 \mathrm{X}_{2}-18.5 \mathrm{X}_{3}+28.2 \mathrm{X}_{4}+$ $6.68 \mathrm{X}_{1}^{2}-6.2 \mathrm{X}_{2}^{2}-3.21 \mathrm{X}_{3}^{2}-1.13 \mathrm{X}_{4}^{2}-3.38 \mathrm{X}_{1} \mathrm{X}_{2}+$ $10.22 \mathrm{X}_{1} \mathrm{X}_{3}-1.81 \mathrm{X}_{1} \mathrm{X}_{4}-0.52 \mathrm{X}_{2} \mathrm{X}_{4}$

TABLE V. MEAN S/N RESPONSE TABLE FOR SURFACE ROUGHNESS AND RESIDUAL STRESS

\begin{tabular}{|c|c|c|c|c|c|c|c|c|c|c|c|c|}
\hline \multirow[t]{2}{*}{ Factor } & \multicolumn{5}{|c|}{ Average surface roughness (Ra) by factor level (dB) } & \multirow[t]{2}{*}{ Rank } & \multicolumn{5}{|c|}{ Maximum residual stress by factor level(dB) } & \multirow[t]{2}{*}{ Rank } \\
\hline & 1 & 2 & 3 & 4 & 5 & & 1 & 2 & 3 & 4 & 5 & \\
\hline $\mathrm{t}$ & $-12.436^{*}$ & -12.87 & -14.56 & -13.46 & -12.45 & 3 & -42.94 & -41.65 & $-41.57 *$ & -42.54 & -43.94 & 2 \\
\hline $\mathrm{n}$ & $-9.79 *$ & -12.41 & -13.84 & -14.88 & -14.85 & 2 & -43.52 & -43.58 & -42.86 & $-41.28 *$ & -41.41 & 3 \\
\hline $\mathrm{f}$ & $-6.007 *$ & -9.104 & -13.34 & -16.97 & -20.35 & 1 & -42.87 & -43.40 & -42.91 & -42.33 & $41.15^{*}$ & 4 \\
\hline $\mathrm{d}$ & -13.86 & -13.41 & -13.55 & -12.75 & $-12.20 *$ & 4 & $-39.65 *$ & -42.71 & -43.31 & -43.61 & -43.37 & 1 \\
\hline
\end{tabular}


TABLE VI. ANALYSIS OF SURFACE ROUGHNESS RA AND MAXIMUM RESIDUAL STRESS RESULTS

\begin{tabular}{|c|c|c|c|c|c|c|c|c|c|c|}
\hline & \multicolumn{4}{|c|}{ Surface roughness, Ra } & \multicolumn{5}{c|}{ Maximum residual stress } \\
\hline Factor & DF & Seq SS & Adj MS & F-ratio & Contribution \% & DF & Seq SS & Adj MS & F-ratio & Contribution \% \\
\hline $\mathrm{t}$ & 4 & 5.966 & 1.491 & 1.03 & 1.97 & 4 & 3980 & 995 & 2.29 & 17.46 \\
\hline $\mathrm{n}$ & 4 & 29.4 & 7.352 & 5.06 & 9.5 & 4 & 4930 & 1232.5 & 2.84 & 21.62 \\
\hline $\mathrm{f}$ & 4 & 252.7 & 63.186 & 43.48 & 82.14 & 4 & 1650 & 412.5 & 0.95 & 7.23 \\
\hline $\mathrm{d}$ & 4 & 7.892 & 1.973 & 1.36 & 2.56 & 4 & 8770 & 2192.5 & 5.05 & 38.46 \\
\hline Error & 8 & 11.627 & 1.453 & & 3.78 & 8 & 3470 & 433.7 & & 15.21 \\
\hline Total & 24 & 307.64 & & & & 24 & 22800 & & & \\
\hline
\end{tabular}

\section{Effect of Turning Parameters on Surface Roughness} Parameters

In this investigation, the average surface roughness $(\mathrm{Ra})$ is considered as the main factor of surface roughness parameters and maximum residual stress that are obviously presented and discussed through RSM methodology. Other surface roughness parameters can be discussed with the same manner followed in this investigation. Figure 4 shows the effects of tool overhang on the average surface roughness at various speeds, feeds and depth of cut, respectively. It can be seen from these figures that tool overhang effect on surface roughness at different speeds is not the same as shown in Figure 4a. At low speed, an increase in tool overhang leads to a slight increase in surface roughness. However, at high speed, an increase in tool overhang results in a considerable increase in the average surface roughness which means the quality of surface deteriorates. This may be due to instability (chatter) increases as the tool overhang length is increased specially at high turning speed. The second interaction is between tool overhang and feed, as shown in Figure 4b. At low feed rate, an increase in tool overhang leads to a slightly increase in average surface roughness, whereas at high speed average surface roughness decreases gradually as the tool overhang is increased. The lowest average surface roughness was obtained with a combination of a very low tool overhang and a very low feed rate. From Figure 4c, it can be realized that at any level of depth of cut the average surface roughness increases as the tool overhang is increased up to $33 \mathrm{~mm}$, whereas the average surface roughness starts to decrease gradually with a further increase in tool overhang. There is a relationship between chatter and tool overhang, and this relationship is not as well appreciated. Changing the tool overhang length changes the overall system and therefore changes the signature frequencies. More experimental work should be carried out to investigate this relationship in detail and try to tune the system by selecting the precise tool overhang that causes a sweet spot to fall at the maximum speed of the spindle.

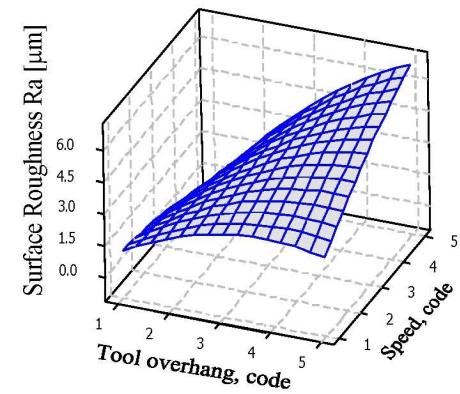

(a)

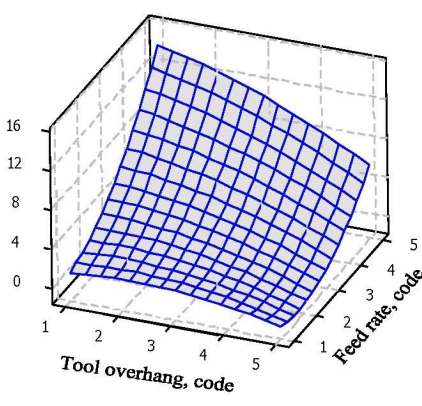

(b)

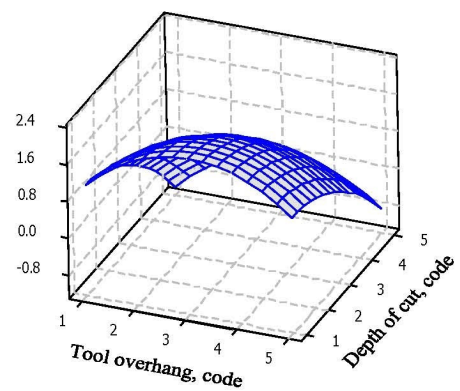

(c)

Fig. 4. Effects of different turning parameters on average surface roughness
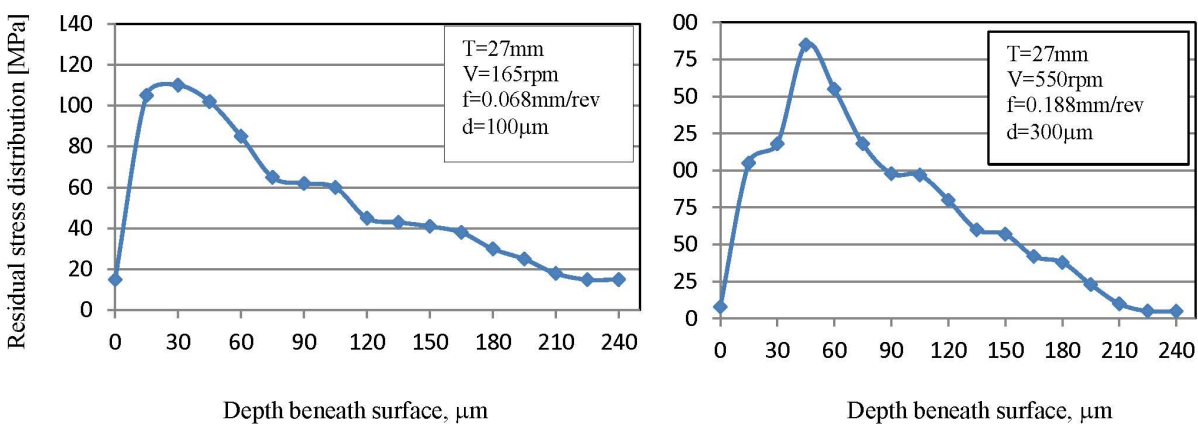

Fig. 5. Residual stress distribution of some experiments carried out according to experimental design matrix 


\section{E. Effect of Turning Parameters on Maximum Residual Stress}

It is known that compressive residual stresses are more favorable for fatigue life than tensile residual stresses. Furthermore, machining of most mechanical components, such as shafts, roller bearing and other mechanical components, is usually mad in a finishing operation and the residual stresses left behind by the machining process remain in the final product, which can be tensile or compressive depending on the used process parameters. Figure 5 shows the results of residual stress distribution for machined specimens, as examples, which have been made according to the experimental design matrix represented in Table IV. It should be pointed out here that the residual stress in most cases starts with very low tensile residual stress and increases to a maximum value at depth in the range from 15 to $45 \mu \mathrm{m}$. The residual stress then decreases gradually with a further increase in depth beneath the machined surface. Figure $6 a$ shows the relationship between maximum residual stress and two different input parameters, tool overhang and rotational speed. Feed rate and depth of cut were kept constant at $0.188 \mathrm{~mm} / \mathrm{rev}$ and $300 \mathrm{~mm}$, respectively. It can be seen that an increase in tool overhang is associated with a decrease in the maximum tensile residual stresses, or a reversion into compressive stress till the compressive residual stresses reach the maximum. This can be attributed to the stability of tool overhang by increasing the tool overhang from 27 to $37 \mathrm{~mm}$. Further increase in tool overhang leads to a decrease in compressive residual stress or to reversion of compressive stresses to tensile stresses. Therefore, higher tool overhangs are more likely to decrease tensile residual stresses. i.e. they are favorable in this concern, since high tensile residual stresses are not desirable as they can lead to cracking and fatigue.

Maximum residual stress is influenced by the change in feed rate coupled with changes in tool overhang. Figure $6 \mathrm{~b}$ shows the effect of tool overhang on maximum residual stress at different feed rates with constant rotational speed and depth of cut, $550 \mathrm{rpm}$ and $300 \mu \mathrm{m}$, respectively. It can be seen that there is an interaction between tool overhang and feed rate. At low tool overhang the maximum tensile residual stress decreases with an increase in feed rate and may be reversed into compressive residual stress at high feed rate as a result of the dominant of mechanical effect due to increasing of cutting forces. However, the tensile residual stress considerably increases with an increase in feed rate at high tool overhang as result of gradually decreasing in the stability of cutting tool by increasing tool overhang more that $37 \mathrm{~mm}$. It is often favorable to have compressive stresses in mechanical parts rather than tensile stresses as the compressive stresses play an important role in the function and service life of these parts. Therefore, it is eminent to set up the cutting conditions in the range which tends to induce compressive stresses or very low tensile residual stress in the work material avoiding conditions inducing high tensile stresses as possible.

The influence of tool overhang on the maximum residual stress at different depth of cut is shown in Figure 6c. All results of this figure, for different combinations of tool overhang and depth of cut at constant speed and feed, tend to be tensile residual stress. It can be seen that the maximum tensile residual stress decreases gradually with an increase in tool overhang up to $37 \mathrm{~mm}$ reaching to a minimum value. Further increase in tool overhang leads to a slightly increase in tensile residual stresses. The best result (low value of maximum tensile residual stress) is obtained at a combination of tool overhang of $37 \mathrm{~mm}$ with very low depth of cut used in this work.

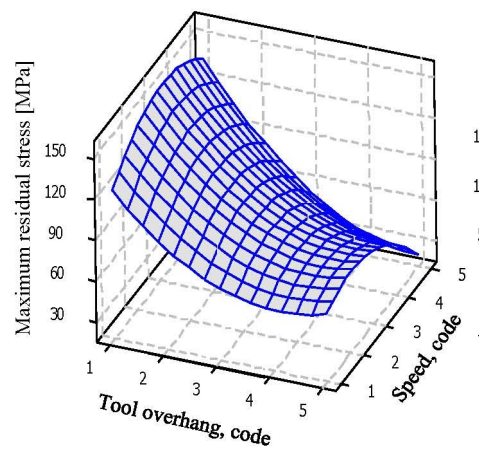

(a)

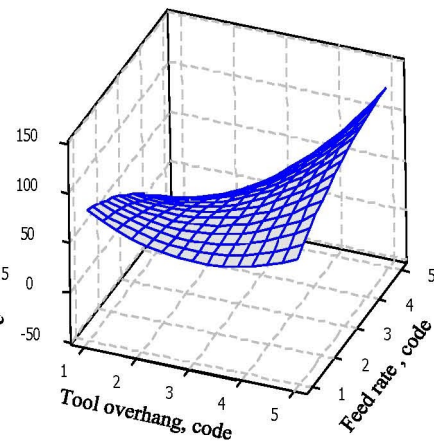

(b)

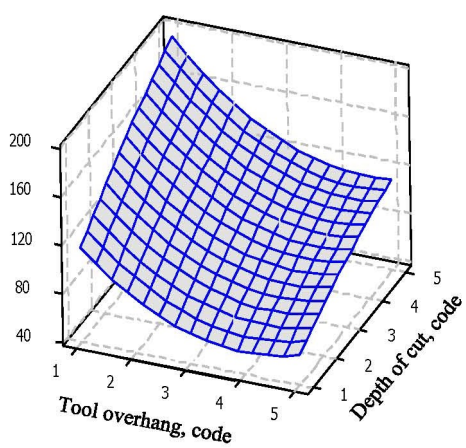

(c)

Fig. 6. Effect of turning parameters on maximum residual stress

\section{CONCLUSIONS}

The influence of turning variables and tool overhang on surface roughness parameters and residual stress induced to a 6061-T6 aluminum alloy due to machining is discussed in this paper. Cutting speed, feed rate, depth of cut and tool overhang are considered. Surface roughness parameters and residual stresses are measured. Based on the analysis of experimental results, the following conclusions can be drawn:

- Second-order surface roughness parameters and maximum residual stress prediction models have been developed. 
Analysis of variance has indicated that these models are adequate for the obtained experimental results.

- Process parameters are optimized using Taguchi relation analysis and the optimum cutting conditions for minimizing surface roughness is t $1 \mathrm{n} 1 \mathrm{fld} 5$ whereas for minimizing tensile residual stress is $\mathrm{t} 3 \mathrm{v} 4 \mathrm{f} 5 \mathrm{~d} 1$.

- Tool overhang interacts with feed rate. The best result of surface roughness was obtained using low or medium values of tool overhang with low speed and/or feed rate.

- Results of this study indicated that surface roughness parameters were most affected by feed rate. For different levels of tool overhang, speed and depth of cut, the average surface roughness considerably increases with an increase in feed rate.

- In machining of 6061-T6 aluminum alloy, there is always a tendency of generation tensile residual stresses, depending on the cutting conditions.

- Minimum tensile residual stress can be obtained with a combination of tool overhang of $37 \mathrm{~mm}$ with very low depth of cut, low rotational speed, and feed rate of 0.188 $\mathrm{mm} / \mathrm{rev}$.

\section{NOMENCLATURE}

$\begin{array}{ll}\text { ANOVA } & \text { Analysis of variance } \\ \mathrm{d} & \text { Depth of cut, } \mu \mathrm{m} \\ \mathrm{DF} & \text { Degree of freedom } \\ \mathrm{F} & \text { Fisher's number } \\ \mathrm{f} & \text { Feed rate, } \mathrm{mm} / \mathrm{rev} \\ \mathrm{MS} & \text { Mean sum of squares } \\ \mathrm{n} & \text { Rotational speed, rpm } \\ \mathrm{Ra} & \text { Roughness Average } \\ \mathrm{Rp} & \text { Maximum Profile Peak Height } \\ \mathrm{Rsm} & \text { Mean Spacing of Profile Irregularities } \\ \mathrm{RSM} & \text { Response surface methodology } \\ \mathrm{Rt} & \text { Maximum Height of the Profile } \\ \mathrm{Rz} & \text { Average Maximum Height of the Profile } \\ \mathrm{S} / \mathrm{N} & \text { Signal-to-noise ratio } \\ \mathrm{SS} & \text { Sum of squares } \\ \mathrm{t} & \text { Tool overhang, mm } \\ \mathrm{X} 1 & \text { Code of tool overhang } \\ \mathrm{X} 2 & \text { Code of rotational speed } \\ \mathrm{X} 3 & \text { Code of feed rate } \\ \mathrm{X} 4 & \text { Code of depth }\end{array}$

\section{REFERENCES}

[1] I. S. Jawahir, E. Brinksmeier, R. M'Saubi, D. K. Aspinwall, J. C. Outeiro, D. Meyer, D. Umbrello, A. D. Jayala, "Surface Integrity in Material Removal Processes: Recent advances", CIRP AnnalsManufacturing Technology, Vol. 60, No. 2, pp. 603-626, 2011
[2] D. A. Axinte, R. C. Dewes, "Surface integrity of hot work tool steel after high speed milling-Experimental data and Empirical models", Journal of Materials Processing Technology, Vol. 127,No. 3, pp. 325-335, 2000

[3] D. Ulutan, T. Ozel, "Machining induced surface integrity in titanium and nickel alloy-A Review", International Journal of Machine Tools and Manufacture, Vol. 51, No. 3, pp. 250-280, 2011

[4] C. J. Rao, D. Nageswara Rao, P. Srihari, "Influence of cutting parameters on cutting force and surface finish in turning operation", Procedia Engineering Vol. 64, pp. 1405-1415, 2013

[5] V. Mishra, G. S. Khan, K. D. Chattopadhyay, K. Nand, R. G. V. Sarepaka, "Effects of tool overhang on selection of machining parameters and surface finish during diamond turning", Measurement, Vol. 55, pp. 353-361, 2014

[6] R. Horvath, A. Dregelyi-Kiss, "Analysis of surface roughness of aluminum alloys fine turned: united phenomenological models and multiperformance optimization”, Measurement, Vol. 65, pp. 181-192, 2015

[7] S. J. Raykar, D. M. D'Addona, A. M. Mane, "Multi-objective optimization of high speed turning of al 7075 using grey relational analysis", Procedia CIRP, Vol. 33, pp. 293-298, 2015

[8] D. Deepak, B. Rajendra, "Investigations on the surface roughness produced in turning of Al6061 (AsCast) by Taguchi Method", International Journal of Research in Engineering and Technology, Vol. 04, No. 8, pp.295-298, 2015

[9] C. R. Liu, M. M. Barash, "Variables governing patterns of mechanical residual stresses in a machined surface", Journal of Engineering for Industry, Vol. 104, No. 3, pp. 257-264, 1982

[10] W. Li, P. J. Withers, W. Preuss, P. Andrews, "Depth and lateral variation of machining-induced residual stress for nickel base superalloy", Material Science Forum, Vol. 681, pp. 332-339, 2011

[11] R. S. Pawade, S. S. Joshi, P. K. Brahmankar, "Effect of machining parameter and cutting edge geometry on surface integrity of high speed turned inconel",. International Journal of Machine Tools and Manufacture, Vol. 48, No. 1, pp. 15-28, 2008

[12] F. Diaz, C. Mammana, A. Guidobono, "Evaluation of residual stresses induced by high speed milling using an indentation method", Modern Mechanical Engineering, Vol .2, No. 4, pp. 143-150, 2012

[13] F. Diaz, C. Mammana, Study of residual stresses in conventional and high speed milling, Nova Science Publishers, Inc., New York, pp. 127156,2012

[14] D. W. Wu, Y. Matsumoto, "The effect of hardness on the residual stresses in orthogonal machining of aisi 4340 steel", Journal of Engineering for Industry, Vol. 112, No. 3, pp. 245-252, 1990

[15] Y. Matsumoto, M. Barash, C. R. Liu, "Effect of hardness on surface integrity of aisi 4340 steel", Journal of Engineering for Industry, Vol. 108, No. 3, pp. 169-175, 1986

[16] M. M. El-Khabeery, M. Fattouh, "Residual stress distribution caused by milling" International Journal of Machine Tool and Manufacture, Vol. 29, No. 3, pp. 391-401,1989

[17] K. H. Fuh, C.F. Wu, "A residual stress model for the milling of aluminum alloy 2014-T6", Journal of Materials Processing Technology, Vol. 51, No. 1-4, pp. 87-105, 1995

[18] D. Y. Jang, T. R. Watkins, K. J. Kozack, C. R. Hubbard, O. B. Cavin, "Surface residual stresses in machined austenitic stainless steel", Wear, Vol. 194, No. 1-2, pp. 168-173, 1996

[19] A. B. Sadat, "Effect of high Speed turning of on surface integrity of 4340 steel", Journal of Material Science and Technology, Vol. 6, pp. 371-375, 1990

[20] D. Ulutan, M. Sima, T. Ozel, "Prediction of machining induced surface integrity using plastic-viscoplastic simulation and temperaturedependent flow softening material model in titanium and nickel- based alloy", Advanced Materials Research, Vol. 223, pp. 401-410, 2011

[21] J. Outeiro, "Optimization of Machining parameters for improved surface integrity of AISI H13 tool steel”, 7th MUGV (Machines et Usinage a Grande Vitesse), pp. 1-10, 2012

[22] P. J. Ross, Taguchi Techniques for Quality Engineering, McGraw-Hill, New York, 1993 
[23] S. Basavarajappa, G. Chandramohan, J. Paulo Davim, "Some studies on drilling of hybrid metal matrix composites based on Taguchi techniques", Journal of Materials Processing Technology, Vol.196, No. $1-3$, pp. 332-338, 2008

[24] D. I. Lalwani, N. K. Mehta, P. K. Jain, "Experimental investigations of cutting parameters influence on cutting forces and surface roughness in finish hard turning of MDN250 steel", Journal of Materials Processing Technology, Vol. 206, No. 1-3, pp. 167-179, 2008

[25] A. Manna, S. Salodkar, "Optimization of machining conditions for effective turning of E0300 alloy steel", Journal of Materials Processing Technology, Vol. 203, No. 1-3, pp. 147-153, 2008

[26] M. Nalbant, H. Gokkaya, G. Sur, "Application of Taguchi method in the optimization of cutting parameters for surface roughness in turning", Matererials \&. Design, Vol. 28, No. 4, pp. 1379-1385, 2007

[27] D. P. Selvaraj, P. Chandramohan, "Optimization of surface roughness of AISI 304 austenitic stainless steel in dry turning operation using Taguchi design method", Journal of Engineering Science and Technology, Vol. 5, No. 3, pp. 293-301, 2010

[28] J. Z. Zhang, J. C. Chen, E. Daniel Kirby, "Surface roughness optimization in an end-milling operation using the Taguchi design method", Journal of Materials Processing Technology, Vol. 184, No. 13, pp. 233-239, 2007

[29] P. H. S. Campos, J. R. Ferreira, A. P. de Paiva, P. P. Balestrassi, J. P. Davim, "Modeling and optimization techniques in machining of hardened steels: a brief review", Reviews on Advanced Material Science, Vol. 34, pp. 141-147, 2013

[30] C. H. Che Haron, A. Ginting, H. Arshad, "Performance of alloyed uncoated and CVD-coated carbide tools in dry milling of titanium alloy Ti-6242S", Journal of Materials Processing Technology, Vol. 185, No. 1-3, pp. 77-82, 2007

[31] M. Nouari, A. Ginting, "Wear characteristics and performance of multilayer CVD-coated alloyed carbide tool in dry end milling of titanium alloy", Surface and Coatings Technology, Vol. 200, No. 18-19, pp. 5663-5676, 2006

[32] O. Belgasim, M. H. El-Axir, "Modeling of residual stresses induced in machining aluminum magnesium alloy (Al-3Mg)", World Congress on Engineering 2010, Vol II, United Kingdom, June 30-July 2, 2010

[33] M. N. Das, N. C. Giri, Design and Analysis of Experiments, 2nd edition, John Wiley, 1980 